\title{
P02.186. CAST (Centella asiatica selected triterpenes): stability, safety, and effect on diabetic neuropathy (DN)
}

\author{
A Soumyanath*, D Dimitrova, G Arnold, H Belding, N Seifer, N Le, J Lou \\ From International Research Congress on Integrative Medicine and Health 2012 \\ Portland, Oregon, USA. 15-18 May 2012
}

\section{Purpose}

The Ayurvedic nerve tonic herb Centella asiatica demonstrates potential neuro-regenerative properties in in vitro and in vivo models. The aims of the present study were to evaluate the safety and therapeutic effects of CAST (Indena ${ }^{\circledR}$, Milan, Italy) in humans with DN, while monitoring the stability of CAST during the trial period.

\section{Methods}

The stability of CAST was monitored throughout the study using reversed phase high performance liquid chromatography. CAST or placebo capsules were administered to $33 \mathrm{DN}$ subjects, in a randomized double-blind, placebocontrolled study. The dose of CAST was escalated from $60 \mathrm{mg}$ to $240 \mathrm{mg} /$ day over the first 12 weeks, followed by a stable dose of $240 \mathrm{mg} /$ day for the remaining 40 weeks. The primary outcome was total symptom score (TSS), while secondary outcomes were nerve conduction studies, neurological disability score (NDS) and qualitative sensory testing (QST).

\section{Results}

CAST was stable $(<10 \%$ change from starting values) at room temperature for the duration of the study. At baseline, there was no difference in outcome measures between treatment $(\mathrm{n}=15,3 \mathrm{~F} / 12 \mathrm{M})$ and placebo $(\mathrm{n}=18$, $6 \mathrm{~F} / 12 \mathrm{M}$ ) groups (TSS: $8.4 \pm 2.9$ vs $8.3 \pm 2.5$; combined sensory nerve action potential amplitude of sural and radial (SNAP): $18.8 \pm 8.9$ vs $17.7 \pm 15.4 \mu \mathrm{V}$ ). At week 52 , subjects in the treatment group had significantly lower TSS scores $(6.4 \pm 0.4$ vs $7.5 \pm 0.4, \mathrm{p}<0.05)$ and higher SNAP $(20.3 \pm 2.4$ vs $14.8 \pm 2.2 \mu \mathrm{V}, \mathrm{p}<0.05)$ than the placebo group. Other

Oregon Health \& Science University, Portland, USA outcome measures did not differ significantly between the two groups.

\section{Conclusion}

CAST was stable and well tolerated by subjects at up to $240 \mathrm{mg}$ per day. Compared to placebo, CAST significantly improved subjective DN symptoms (TSS score) and prevented deterioration in an objective measure of nerve conduction (SNAP). Current treatments for DN provide symptomatic relief rather than ameliorating disease progression. Multicenter trials are clearly warranted to further evaluate the role of CAST as a novel disease-modifying agent for DN.

Published: 12 June 2012

doi:10.1186/1472-6882-12-S1-P242

Cite this article as: Soumyanath et al.: P02.186. CAST (Centella asiatica selected triterpenes): stability, safety, and effect on diabetic neuropathy (DN). BMC Complementary and Alternative Medicine 2012 12(Suppl 1):P242.

Submit your next manuscript to BioMed Central and take full advantage of:

- Convenient online submission

- Thorough peer review

- No space constraints or color figure charges

- Immediate publication on acceptance

- Inclusion in PubMed, CAS, Scopus and Google Scholar

- Research which is freely available for redistribution 